\title{
Non-Convulsive Status Epilepticus Features with Electroencephalography Monitoring in the Neurological Intensive Care Unit: A Prospective Study
}

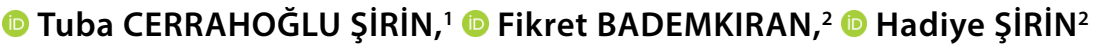

'Department of Neurology, University of Health Sciences, Şişli Hamidiye Etfal Training and Research Hospital, İstanbul, Turkey

${ }^{2}$ Department of Neurology, Ege University Faculty of Medicine, İzmir, Turkey

\begin{abstract}
Objectives: Since non-convulsive status epilepticus (NCSE) is a reversible cause of coma and/or change in consciousness in the neurological intensive care unit (NICU), its early diagnosis and treatment are necessary. Continuous electroencephalography monitoring (cEEG) is an important diagnostic tool, but since access to CEEG may be limited, it is critical to choose which patients will be referred to $c E E G$ for diagnosing NCSE. In our study, we aimed to investigate patients with an unexplained altered level of consciousness who should be directed to cEEG according to clinical features and emergency EEG (EmEEG) features.

Methods: In 40 consecutive patients who were admitted to the NICU and whose reason for the altered mental status could not be explained, $30 \mathrm{~min}$ EmEEG and cEEG starting in the first $24 \mathrm{~h}$ were performed and their clinical features, Glasgow Coma Score (GCS), four score (FS), and prognosis were noted.

Results: The frequency of NCSE was $22.5 \%$. cEEG did not detected NCSE in patients who were not diagnosed in the EmEEG. No causality relationship was found between NCSE etiology, low GCS score, low FS, and the level of consciousness. The 55\% of the NCSE patients had minor motor movements. The poor prognosis was $55 \%$ in the NCSE patients, but it did not differ significantly from the non-NCSE patients. In conclusion, EmEEG is a useful tool for NCSE screening in NICU patients at the early phase of changes in consciousness. Apart from minor motor movements, clinical and history characteristics do not predict the high NCSE risk. The unfavorable prognosis is probably related to the underlying etiology and is not affected by the presence of NCSE.

Conclusion: When there is no access to CEEG, EmEEG may be helpful for the diagnosis of NCSE in the early clinical period. The presence of minor motor movements and EmEEG findings together can be useful tools to guide high-risk patients with NCSE to cEEG monitoring.

Keywords: Electrographic seizure; neurological intensive care; non-convulsive seizure; status epilepticus.
\end{abstract}

Cite this article as: Cerrahoğlu Şirin T, Bademkıran F, Şirin H. Non-Convulsive Status Epilepticus Features with Electroencephalography Monitoring in the Neurological Intensive Care Unit: A Prospective Study. Epilepsi 2021;27:183-191.

\section{Introduction}

In the Neurological Intensive Care Unit (NICU) patients with an unexplained altered level of consciousness, it is important to diagnose and treat non-convulsive status epilepticus (NCSE) on time because a delay in treatment may result in neuronal damage. ${ }^{[1]}$ Continuous electroencephalography

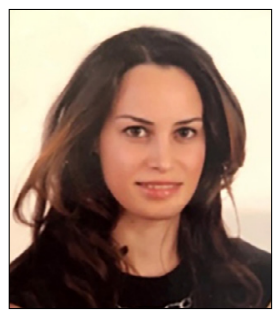

Corresponding author

Tuba CERRAHOĞLU ŞİRIN, M.D.

e-mail tubacerrahoglu@hotmail.com

Received 25.11.2020

Accepted 11.03.2021

Online date 09.08 .2021

Content of this journal is licensed under a Creative Commons Attribution-NonCommercial 4.0 International License.

Tuba CERRAHOĞLU ȘIRIN, M.D.
(cEEG) may be necessary to diagnose, since non-convulsive seizures (NCSs) cannot be detected with clinical clues in patients with an altered level of consciousness during an acute neurological event or in a coma. However, obtaining the CEEG for diagnosing NCSE can often be difficult due to limited resources. Moreover, unnecessary use of cEEG resources, especially for low-risk patients, will cause delays for high-risk patients.

In comatose patients, $90 \%$ of the seizures recorded are non-convulsive. ${ }^{[2,3]}$ In addition, in NCSE patients with coma, prognosis is poor with a mortality rate up to $50 \% .^{[4-6]}$ Early diagnosis and treatment of NCSE or NCS is critical as it will prevent high mortality and morbidity. Especially, if the treatment is still not initiated within 30 min after the onset of $\mathrm{SE}$, mortality is high and the functional status is worse at discharge..$^{[7]}$ 


\section{Nörolojik Yoğun Bakım Ünitesinde EEG Monitorizasyonuyla Nonkonvülzif Status Epileptikus Özellikleri: İleriye Yönelik Bir Çalışma}

\section{Öz}

Amaç: Nörolojik yoğun bakım ünitesinde (NYBÜ), nonkonvülzif status epileptikus (NKSE) geri dönüşümlü bir koma ve/veya bilinç değişikliği nedeni olduğu için erken tanı konulup tedavi edilmelidir. Devamlı EEG monitorizasyonu (cEEG) gerekli olabilecek bir tanı aracıdır, ancak cEEG'ye erişim sınırlı olabileceğinden, NKSE teşhisi için hangi hastaların cEEG'ye yönlendirileceğini seçmek kritiktir. Çalışmamızda, klinik özelliklere ve acil EEG özelliklerine göre CEEG'ye yönlendirilmesi gereken açıklanamayan bilinç bozukluğu olan hastaları araştırmayı amaçladık.

Gereç ve Yöntem: Nörolojik yoğun bakım ünitesine kabul edilen ve bilinç bozukluğunun nedeni açıklanamayan 40 ardışık hastaya ilk 24 saatte başlayan acil 30 dakikalık rutin EEG ve cEEG yapıldı. Klinik özellikleri, Glasgow koma skoru (GKS), FOUR Skor (FS) ve prognoz not edildi.

Bulgular: Nonkonvülzif status epileptikus sıklığı \%22.5'ti. Acil 30 dakikalık EEG'de NKSE saptanmayan hastalarda, cEEG de NKSE tespit etmedi. Etiyoloji, düşük GKS skoru, düşük FS ve düşük bilinç düzeyi ile NKSE arasında nedensellik ilişkisi bulunmadı. NKSE hastalarının \%55'inde minör motor hareketler vardı. Kötü prognoz, NKSE hastalarında \%55'ti, ancak NKSE olmayan hastalardan istatistiksel olarak farklı değildi.

Sonuç: Acil EEG, NYBÜ hastalarında bilinç değişikliklerinin erken evresinde NKSE taraması için yararlı bir araçtır. Minör motor hareketler dışında, klinik ve geçmiş özellikler yüksek NKSE riskini öngörmez. Olumsuz prognoz muhtemelen altta yatan etiyoloji ile ilişkilidir ve NKSE'nin varlığından etkilenmez. CEEG'ye erişim olmadığında, acil EEG, erken klinik dönemde NKSE tanısı için yardımcı olabilir. Minör motor hareketlerin ve acil EEG bulgularının birlikte varlığı, NKSE için yüksek riskli hastaları cEEG izlemeye yönlendirmek için yararlı araçlar olabilir.

Anahtar sözcükler: Elektrografik nöbet; nonkonvülziv nöbet; nörolojik yoğun bakım; status epileptikus.

This study aims to better understand the risk factors, characteristics, and prognosis of patients with NCSE in the NICU. We hypothesized that NCSE may be underdiagnosed in critically ill neurological patients. We aimed to investigate the rate of predicting NCSE risk by clinical examination and medical history, the rate of determining the diagnosis of emergency short-term EEG (EmEEG) compared with the cEEG taken in the first $24 \mathrm{~h}$, and which patients should be referred to $c E E G$.

\section{Materials and Methods}

The study was conducted in a prospective cohort aged 18 and over who were consecutively admitted to the NICU within 7 months during the first $24 \mathrm{~h}$ of change in consciousness. The protocol was approved by the ethical committee of the Ege University, Faculty of Medicine (no: 11-1.1/13), and it complied with the Declaration of Helsinki. Informed consent was obtained from the legal parents of all patients.

Emergency EEG (EmEEG) for 30 min within the first $2 \mathrm{~h}$ of consciousness change, and CEEG monitoring for at least 12 $\mathrm{h}$, which starts within the first $24 \mathrm{~h}$, was performed to all patients. When EEG was indicated, the EEG recordings were conducted digitally at the bedside with the NicoletOne EEG device. EEG was placed with scalp electrodes according to the international 10-20 system. The recordings were evaluated using standard electrophysiology criteria by a neurophysiologist who knew the patient's clinical condition and history.

Patient Selection- Patient selection was made according to the following criteria:
1. Patients who are admitted to the NICU with an unexplained altered level of consciousness

2. The NICU patients whose level of consciousness did not return to baseline after the appropriate treatment of clinical epileptic seizures

3. The NICU patients with an altered level of consciousness unexplained by their hospitalization diagnosis.

Clinical, demographic, electrophysiological findings, history of previous epileptic seizures, epilepsy risk factors, and prognostic features were noted. All patients were examined by cranial MRI, metabolic profile, and, when necessary, cerebrospinal fluid (CSF) examination to investigate the etiology of the altered level of consciousness. Patients who had a convulsive SE after the change in consciousness and patients whose decreased level of consciousness recovered spontaneously were excluded from the study.

Electroencephalogram Classification- EEG findings were categorized according to the American Society of Clinical Neurophysiology's standardized critical care EEG terminology: ${ }^{[8]}$ (i) Normal; (ii) slowing and asymmetry (rhythmic delta activities, generalized, bilateral independent, and non-rhythmic theta/delta slowing); (iii) sharp and wave (spike and wave, multiple spike and wave, and sharp and wave); (iv) periodic discharges (generalized periodic discharges, lateralized periodic discharges, and bilateral independent lateralized periodic discharges); (v) ictal patterns (NCSE and electrophysiological seizures); (vi) burst suppression; and (vii) electrocerebral silence.

The diagnosis of NCSE was made according to the previously defined criteria, and the following diagnostic criteria were 
used: Frequent or continuous focal electrographic seizures in the form of an ictal pattern with changes in amplitude, frequency, and/or spatial distribution; frequent or continuous generalized spike and wave discharges in patients with no previous history of epilepsy syndrome; frequent or continuous generalized spike and wave discharges with significant changes in intensity or frequency (usually a faster frequency) compared to baseline EEG in patients with a history of epilepsy syndrome; and periodic discharges developed in patients in coma following generalized tonic-clonic $\mathrm{SE} .{ }^{\left[{ }^{[9]}\right.}$ The seizures were clinically determined as convulsive or non-convulsive. NCSE subtypes were defined according to their clinical and electrophysiological characteristics. ${ }^{[10]}$ After the completion of our study, it was recommended to use Salzburg Criteria in the diagnosis of NCSE to better distinguish false-positive cases in 2015, and the reliability of the criterion was shown in subsequent studies. ${ }^{[1]]}$

Clinical Evaluation- The etiology that might be responsible for SE etiology was classified according to ILAE recommendations: Acute symptomatic (first 7 days; acute extensive ischemic stroke, acute cerebral hemorrhage, acute CNS infection, severe systemic infection, chronic renal failure requiring dialysis, and metabolic disorder), remote symptomatic (old trauma, old stroke, old CNS infection, and dementia), progressive symptomatic, SE in defined electroclinical syndromes, and cryptogenic. ${ }^{[10]}$

The patients' level of consciousness was classified as: (1) Awake confused; (2) lethargic (inducible and responsive); (3) stupor (inducible but unresponsive); and (4) coma. Glasgow Coma Score (GCS) and four score (FS) were used to evaluate the level of consciousness during EEGs. Ocular movement disorders such as nystagmus, eye deviation, subtle twitches, and automatisms in the face and extremities that were observed clinically during monitoring were noted in the case file.

Failure to respond despite the administration of IV benzodiazepine (BZD) followed by at least one sufficient dose of proper antiepileptic treatment, and the continuation of the SE episode was defined as "resistant SE."[12] "Super-resistant $\mathrm{SE}^{\prime}$ was defined as persistent or recurrent SE $24 \mathrm{~h}$ after the anesthetic drug initiation, or recurrent SE when the anesthetic drug was reduced. The management of the patients' medication was done by the NICU physicians; the researchers did not interfere with the treatment.

The prognosis was evaluated as favorable and unfavorable. The partial or complete level of consciousness with functional improvement at discharge (at least providing functional performance in daily life activities) was included in the favorable prognostic group; and patients who could not achieve neurological improvement at discharge, who were completely dependent on daily life activities, or who died constituted the unfavorable prognostic group.

The main purpose of this study was to determine the frequency of NCSE in the NICU and the relationship of NCSE with etiological factors and poor prognosis. Data were collected and analyzed in terms of etiology, clinical and EEG features, and prognosis of the patients according to the presence of NCSE.

Statistical Analysis- For comparison, patients were divided into two groups as NCSE and non-NCSE. The distribution of the data was analyzed with the Kolmogorov-Smirnov test. Mann-Whitney U-test was used to analyze quantitative data. The qualitative data analyzed with Chi-square test; Fisher's test was used when Chi-square conditions were not met. Logistic regression analysis was performed to investigate causality and the results were given as odds ratio (OR). SPSS 21.0 program was used in the analyses.

\section{Results}

Consecutive 45 patients were enrolled in the study. After the first EEG, five patients (one patient died, one had decompression operation, one had convulsive $\mathrm{SE}$, and two patients' level of consciousness returned to baseline spontaneously) were excluded from the study. The average age of 40 patients was 60.8 years (19-88 years) and $24(60 \%)$ were women. NCSE was detected in $9(22.5 \%)$ of the patients. The average age of patients with NCSE was 54 years and $78 \%$ were women. In the NCSE and non-NCSE patients, the age and gender distribution, the presence of epilepsy, and the rates of epileptic seizures just before the altered level of consciousness were similar (Table 1). The most common NICU hospitalization diagnoses were ischemic stroke (30\%), toxic/metabolic encephalopathy (17.5\%), and structural brain lesions (17.5\%) (Table 2).

EEG Features- EEG was indicated in 17 of the patients (42.5\%) because the level of consciousness did not return to baseline after epileptic seizure and 23 (57.5\%) of them had unexplained decreased level of consciousness in the form of agitation, stupor, or sudden deterioration in neurological condition. Median duration of CEEG was 29.1 h, 24 (60\%) patients had EEGs longer than $24 \mathrm{~h}$; the longest times were 3 days, 5 days, and 1 week.

The EEG findings were all abnormal. Table 3 shows the EEG patterns of the patients. NCSE was detected in 22.5\% (9/40) of the patients. When EEGs were reevaluated retrospectively, 
Table 1. Demographic and clinical characteristics of patients

\begin{tabular}{|c|c|c|c|c|}
\hline & $\operatorname{NCSE}(n=9)$ & Non-NCSE $(n=31)$ & $\mathrm{p}$ & OR \\
\hline $\operatorname{Age}^{*}$ & $54 \pm 20.6$ & $63 \pm 17.7$ & 0.18 & \\
\hline \multicolumn{5}{|l|}{$\operatorname{Sex}^{* *}$} \\
\hline Female/male & $78 \% 8(7) / 22 \%(2)$ & $55 \%(17) / 45 \%(17)$ & 0.21 & \\
\hline Preexisting epilepsy ${ }^{* * * *}$ & $11.1 \%(1)$ & $3.2 \%(1)$ & 0.33 & 3.75 \\
\hline Seizure before administration ${ }^{* * * *}$ & $66.7 \%(6)$ & $35.5 \%(11)$ & 0.09 & \\
\hline Focal motor & $22.2 \%(2)$ & $9.6 \%(3)$ & 0.32 & 2.66 \\
\hline Generalized tonic clonic & $44.4 \%(4)$ & $25.8 \%(8)$ & 0.28 & 2.30 \\
\hline \multicolumn{5}{|l|}{ Awareness level on EEG day** } \\
\hline Confusion & $33.3 \%(3)$ & $16.1 \%(5)$ & 0.48 & \\
\hline Lethargic & $11.1 \%(1)$ & $32.3 \%(10)$ & & \\
\hline Stupor & $44.4 \%(4)$ & $35.5 \%(11)$ & & \\
\hline Coma & $11.1 \%(1)$ & $16.1 \%(5)$ & & \\
\hline GCS on EEG day ${ }^{*}$ & $9 \pm 3.54$ & $9.74 \pm 3.49$ & 0.57 & \\
\hline $\mathrm{GCS}<8^{* * *}$ & $33.3 \%(3)$ & $22.6 \%(7)$ & 0.51 & 1.7 \\
\hline FS on EEG day ${ }^{*}$ & $11.44 \pm 3.36$ & $12.16 \pm 3.22$ & 0.56 & \\
\hline $\mathrm{FS}<8^{* * *}$ & $22.2 \%(2)$ & $16.1 \%(5)$ & 0.67 & 1.4 \\
\hline Minor motor activities ${ }^{* * *}$ & $55.6 \%(5)$ & $25.8 \%(8)$ & 0.09 & 3.59 \\
\hline \multicolumn{5}{|l|}{ ICU hospitalization etiology ${ }^{* * *}$} \\
\hline Ischemic stroke & $11.1 \%(1)$ & $35.5 \%(11)$ & 0.13 & 0.22 \\
\hline Intracerebral hematoma & $0 \%(0)$ & $12.9 \%(4)$ & 0.99 & 0.0 \\
\hline CNS infection & $22.2 \%(2)$ & $6.4 \%(2)$ & 0.19 & 4.1 \\
\hline Convulsive SE & $11.1 \%(1)$ & $3.2 \%(1)$ & 0.36 & 3.7 \\
\hline Encephalopathy & $11.1 \%(1)$ & $19.4 \%(6)$ & 0.57 & 0.52 \\
\hline Other & $44.4 \%(4)$ & $22.6 \%(7)$ & 0.20 & 2.7 \\
\hline Unfavorable outcome ${ }^{* * *}$ & $55.6 \%(5)$ & $71 \%(22)$ & 0.38 & 0.51 \\
\hline Mortality & $44.4 \%(4)$ & $54.8 \%(17)$ & 0.58 & \\
\hline New neurological deficits at discharge ${ }^{* *}$ & $22.2 \%(2)$ & $22.5 \%(7)$ & 0.98 & \\
\hline Returning to the initial neurological state** & $33.3 \%(3)$ & $25.8 \%(8)$ & 0.68 & \\
\hline
\end{tabular}

"Mann-Whitney U test; "“Chi-square test; "'-Univariate logistic regression analysis. NCSE: Non-convulsive status epilepts; EEG: Electroencephalography; CNS: Central nervous system; GCS: Glasgow Coma Score; ICU: Intensive care unit.

all of those diagnosed with NCSE met NCSE criteria according to the Salzburg Criteria: 5 (55.5\%) patients had a rhythmic periodic pattern with a frequency $>2.5 \mathrm{~Hz} ; 4$ had a $\leq 2$ $\mathrm{Hz}$ rhythmic periodic pattern with typical evolution (Table 4).

Of the nine cases diagnosed with NCSE, two had encephalitis, two had structural brain lesions, one had metabolic encephalopathy, one patient with epilepsy had convulsive SE before the consciousness alteration, and two patients diagnosed as de novo absence SE by observing typical 3-4 Hz spike wave activity in EEGs (Table 2). Patients with de novo absence SE had no history of childhood epilepsy, psychotropic drug or toxin exposure, or drug withdrawal, and their brain MRIs and CSF examinations were normal.

The onset of NCSEs observed on EEG was 67\% (6/9; 4 frontal, 2 temporal origin) focal and 33\% (3/9) generalized.
Among the NCSE patients, 55.5\% (5/9) did not have seizures after the first AED treatment, $22.2 \%$ (2/9) had a super-resistant NCSE pattern, and $33.3 \%$ (3/9) had recurrent NCSE. Patients whose 30 min EmEEG recordings showed no signs of NCSE were also not diagnosed with NCSE after a cEEG monitoring.

NCSE Clinical Features- Between the NCSE and non-NCSE patients, no statistically significant difference was found in the level of consciousness at the time of administration, the GCS and FS scores at the time of EEGs, and presence of minor motor movements at the time of administration/follow-up (Table 1). The sensitivity of minor motor movements for NCSE was $55 \%$, but it was not statistically significant $(p=0.096)$. There were $17(42.5 \%)$ patients with decreased consciousness beginning with convulsive seizures. However, among these 17 patients, there was no statistically sig- 
Table 2. Intensive care admission diagnosis of all patients. Other structural brain lesions include etiologies other than stroke and encephalitis that can be demonstrated by imaging methods such as white matter diseases, brain metastases, and central nervous system lymphoma. After the follow-up of the patients with unexplained changes in consciousness, two patients were diagnosed with de novo absence status epilepticus, and two patients without NCSE diagnosed with possible variant Creutzfeldt-Jakob disease

\begin{tabular}{lcc}
\hline Intensive care admission diagnosis & $\begin{array}{c}\text { All } \\
\text { patients } \\
\mathrm{n}(\%)\end{array}$ & $\begin{array}{c}\text { NCSE } \\
\text { patients } \\
\mathrm{n}(\%)\end{array}$ \\
\hline Ischemic stroke & $12(30)$ & $1(8.3)$ \\
Toxic/metabolic encephalopathy & $7(17.5)$ & $1(14.2)$ \\
Central nervous system infection & $4(10)$ & $2(50)$ \\
Convulsive status epilepticus & $2(5)$ & $1(50)$ \\
Hemorrhagic stroke & $4(10)$ & $0(0)$ \\
Other structural brain lesions & $7(17.5)$ & $2(28.5)$ \\
Impaired consciousness of & $4(10)$ & $2(50)$ \\
unknown cause & & \\
\hline
\end{tabular}

NCSE: Non-convulsive status epilepticus.

Table 3. Distribution of electroencephalography characteristics of all patients

\begin{tabular}{lc}
\hline & No. (\%) \\
\hline Normal & $0(0)$ \\
Slow and asymmetry & $40(100)$ \\
Sharp and wave & $6(15)$ \\
Periodic discharges & $2(5)$ \\
Ictal pattern/NCSE & $9(22.5)$ \\
Burst suppression & $0(0)$ \\
Electrophysiologic silence & $0(0)$ \\
\hline
\end{tabular}

NCSE: Non-convulsive status epilepticus.

nificant difference between NCSE and non-NCSE groups in diagnosing NCSE (Table 1).

When the distribution of NCSE subgroups was examined; $80 \%(4 / 5)$ were classified as focal NCSE, 33\% (3/9) absence NCSE, and 22\% (2/9) NCSE with coma. Unilateral minor motor movements were clinically accompanying in 60\% (3/5) of patients with focal NCSE (Table 4).

BZD or antiepileptic treatment was not given to any patient before an emergent EEG. Two patients were already using

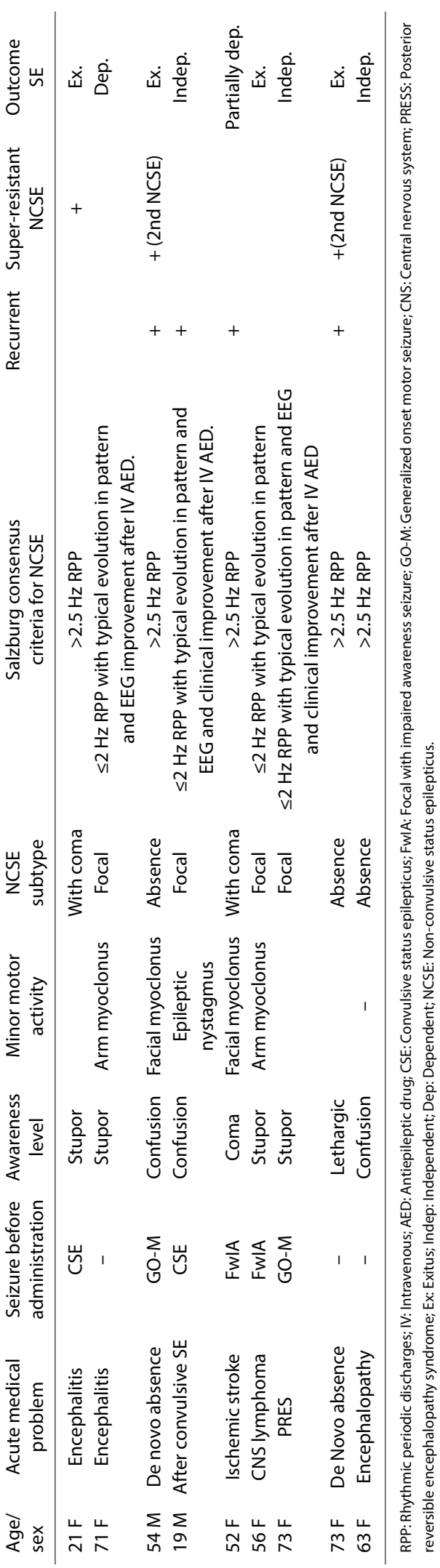


daily routine antiepileptic drugs due to the diagnosis of epilepsy at admission. When the treatment response of the NCSE patients was evaluated; NCSE was terminated after BZD in 44.4\% (4/9) of the patients and after the second antiepileptic drug in $44.4 \%(4 / 9)$, but in $11.1 \%(1 / 9)$, NCSE continued despite advanced treatments (super-resistant NCSE). In $44.4 \%$ (4/9) of the cases, NCSE recurred for the second time, and, at second NCSE period, $22.2 \%$ (2/9) of the cases recovered with BZD but $22.2 \%(2 / 9)$ had super-resistant NCSE (Table 4). Totally, super-resistant NCSE was observed in $33.3 \%$ ( $3 / 9 ; 1$ encephalitis, 2 de novo absences). The electrophysiological response of the patients who responded to the treatment to the antiepileptic drug started in the first 15 $\mathrm{min}$, but the clinical recovery of their cognition varied from $2 \mathrm{~h}$ to $12 \mathrm{~h}$.

While the unfavorable prognosis rate was $55.5 \%(5 / 9)$ in the NCSE patients, it was $71 \%(7 / 31)$ in the non-NCSE group. When the two groups were compared, the presence of NCSE was not associated with an unfavorable prognosis (Table 1). The rates of new neurological deficits at discharge and the rates of returning to baseline neurological status after discharge were similar in the NCSE and non-NCSE patients (Table 1).

The mortality rate was $44.4 \%(4 / 9)$ in the NCSE patients which was no different than non-NCSE patients. One of the NCSE patients who died had CNS lymphoma. The remaining three patients who died were those who had super-resistant NCSE, despite burst suppression with an anesthetic agent, and died due to disseminated intravascular coagulopathy after a hospital infection. Mortality rates did not differ significantly between generalized onset $(66.6 \% ; 2 / 3)$ and focal onset $(33.2 \% ; 2 / 6)$ NCSE. The GCS and FS scores of the NCSE patients were not causally related to the prognostic outcomes of the patients. There was no significant difference between the length of hospital stay of the NCSE and non-NCSE patients.

\section{Discussion}

In our study, the incidence of NCSE was $22.5 \%$ in the NICU patients with an unexplained altered level of consciousness. CEEG did not detect NCSE in patients who were not diagnosed in the $30 \mathrm{~min}$ EmEEG. The demographic features (age, sex, and preexisting epilepsy), etiologic factors, and clinical outcomes were not different from the non-NCSE group. The patient's initial low GCS and FS scores and decreased level of consciousness did not indicate the presence of NCSE. Minor motor movements were observed in more than half of the patients with NCSE. The rate of poor prognosis is high, but it does not differ between patients with and without
NCSE $(55.6 \%$ and $71 \%$, respectively). Finally, the low GCS and FS scores at administration do not predict prognosis. The incidence of NCSE in our study is consistent with the incidence reported in the range of $8-31 \%$ in comatose and critically ill patients in previous prospective and retrospective observational studies. ${ }^{[2,3,13-16]}$ When evaluated specifically in the NICU, the frequency of seizures increases, although it varies depending on the intensity of monitoring. In patients who became comatose following convulsive $\mathrm{SE}$, the frequency of NCSE/NCS increases up to $48 \%{ }^{\left[{ }^{[17]}\right.}$

CEEG is an important diagnostic tool for NCSE. Twenty-four hours CEEG monitoring for NCSE screening in non-comatose patients with an altered level of consciousness and $48 \mathrm{~h}$ CEEG monitoring in comatose patients are recommended. ${ }^{[2]}$ However, it is not practical to record a cEEG for every patient with an altered level of consciousness. When all ICU patients undergoing EEG monitoring were analyzed retrospectively, it was reported that CEEG was more effective than routine 20 min EEG in diagnosing NCSE. ${ }^{[3]}$ Furthermore, when the CEEG recordings were extended to 7-10 days after traumatic brain injury, NCS was found in $52 \%$ of intensive care patients. ${ }^{[18]}$ In NICU, Narayanan and Murthy prospectively examined all patients with the altered level of consciousness and reported that EmEEG is not as specific as CEEG in terms of diagnosing NCSE. ${ }^{[19]}$ In our study, no difference was found between EmEEG and CEEG in terms of diagnosing NCSE in patients with an unexplained altered level of consciousness in NICU. The reason for this can be explained by the relatively shorter duration of CEEG monitoring in our cases and, unlike the previous studies, diagnoses that increase the risk of seizures such as hypoxic encephalopathy, traumatic brain injury, and brain abscess was not found in our study population, but only primary neurological diseases were included.

Due to limited resources (e.g., a single device), it should be chosen which patients should be prioritized for CEEG monitoring. Therefore, EmEEG may become a useful utility tool for patients with altered mental status. In retrospective evaluation, although a short-term EmEEG can only diagnose $10 \%$ NCSE in the general patient group, ${ }^{[20]}$ it can diagnose 2 times more in ICU patients compared to ward patients, ${ }^{[21]}$ however, in selected cases in NICU, EmEEG is $96.3 \%$ useful for NCSE. ${ }^{[22]}$ In addition, the early emergence of NCSE in critical patients in NICU also increases the importance of EmEEG. It should be noted that retrospective cEEG studies have shown the first NCS in $58-74 \%$ of critically ill patients in the first $30 \mathrm{~min}^{[23,24]}$ in $56-73 \%$ in the $1 \mathrm{st} \mathrm{h}$ after the change in consciousness, ${ }^{[2,6]}$ and $66-93 \%$ in the first $12 \mathrm{~h} \cdot{ }^{[6,16]}$ In our patient group, an EmEEG was performed as soon as unexplained altered level of consciousness occurred and 
the similar detection rates in EmEEGs and CEEGs were observed due to EmEEG scans were recorded in the early period, approximately within the first $2 \mathrm{~h}$ after the beginning of change in consciousness. Nevertheless, our findings indicate that EmEEG can be quite stable in diagnosing NCSE in the early period and suggest that EmEEG can be helpful in cases where CEEG monitoring opportunities are limited.

Interictal EEG findings are associated with the likelihood of seizures. For this reason, EmEEG can continue to be a helpful tool when it fails to diagnose NCSE. While the background activity is normal in EEG, the seizure probability decreases. The loss of reactivity on EEG, epileptiform discharges, lateralized rhythmic delta activities, periodic lateralizing discharges, short potentially ictal rhythmic discharges, and a burst suppression pattern increase the likelihood of seizures. ${ }^{[23,25-27]}$ Recently, after $1 \mathrm{~h}$ of EEG monitoring for NCSE risk factor, $24 \mathrm{~h}$ cEEG monitoring was recommended for patients who has 2 points or more in the 2HELPS2B scale which scores EEG features and clinical findings and if the score is 0 , no $C E E G$ is required. ${ }^{[28]}$ Although interictal changes may be associated with the likelihood of seizures, we could not find such a relationship between interictal changes and NCSE in our findings.

Studies examining similar patient groups have shown that clinical features such as eye deviation, nystagmus, or twitching in the NCSE patients are more likely than other causes of impaired consciousness. ${ }^{[14,29]}$ Therefore, it is thought that the presence of minor motor movements may be useful in selecting patients for EEG, but no clinical feature has been found to have high sensitivity and specificity for NCSE. In our study, although it does not differ significantly from the non-NCSE patients, the presence of accompanying minor motor movements in more than half of the NCSE patients supports that it can be used as a clinical clue for choosing who to have an EmEEG among patients with a decreased level of consciousness.

A high risk of NCSE association with a history of epilepsy, previous CNS infection, and past CNS tumors has been reported, and in addition, acute cerebral events such as ischemic stroke, intracerebral hemorrhage, and CNS infection, and traumatic brain injury are frequently associated with NCSE. ${ }^{[2,14,30]}$ Furthermore, coma has been defined as one of the clinical parameters associated with the NCSE occurrence. ${ }^{[2,24,27]}$ Although ischemic stroke, intracerebral hemorrhage, and structural brain lesion diagnoses are frequent reasons for hospitalization in our NICU, no causality relationship was found between the increased NCSE risk and etiological factors in our study. Similarly, although coma was reported as an independent predictor of NCSEs in ICUs, we could not find a correlation between lower GCS or FS scores and NCSE occurrence.

In NCSE, it is not clear whether the seizures are a biomarker of severe brain damage or whether the seizures themselves contribute to the poor prognosis. The first opinion is that the main determinant of prognosis in NCSE depends on the underlying etiology, ${ }^{[4,31]}$ especially potentially fatal ones. ${ }^{[32,33]}$ Acute stroke has been shown to be associated with a worse prognosis compared to other etiologies. ${ }^{[34,35]}$ Moreover, in patients with NCSE after SAH, mortality may exceed $80 \% \cdot{ }^{[36,37]}$ On the contrary, remote symptomatic causes compared to acute symptomatic NCSE cases, ${ }^{[38]}$ and NCSE associated with epilepsy compared to NCSE associated with other serious medical problems ${ }^{[4,39]}$ has lower mortality rates. The other opinion has advocated that the presence of NCS/ NCSE in comatose patients reflects severe brain damage and carries a high mortality risk. ${ }^{[39]}$ In addition, few studies have suggested that increased seizure burden independent of etiology is the main determinant of poor prognosis..$^{[40,41]}$

The mortality rates of NCSE patients in the ICU have been reported as $20-57 \%$ and as the initiation time of treatment is delayed for more than $3 \mathrm{~h}$, the mortality and poor functional outcome increase. ${ }^{[4-6]}$ Furthermore, it was found that NCSE patients had higher mortality rates than non-NCSE patients and the NCSE mortality correlated to the severity of coma. ${ }^{[15]}$ In our study, the unfavorable prognosis is $67.5 \%$ in the whole population and the death rate is relatively high $(52.5 \%)$. This may be due to the underlying pathology being more severe or more advanced in patients with impaired consciousness of unknown cause. Furthermore, in NCSE patients, there was no causality relationship between low GCS and FS scores and the prognosis. We found that the unfavorable prognosis rates of the NCSE and non-NCSE patients and returning to the initial neurological state at discharge were similar, which supports that the underlying etiology, not the presence of NCSE, affects the prognosis. Since we diagnosed and treated patients early, we could not determine the effect of NCSE on prognosis. Therefore, we may only have seen the effect of primary etiology, which is the reason for the patients' admission to the NICU, on prognosis.

In our study, NCSE patients were classified as $55 \%$ focal onset and $45 \%$ generalized onset NCSE according to EEG features. Classification of NCSE subtype is important as it will be a guide in terms of treatment selection and prognosis. While lateralizing NCSE was observed most frequently in $50 \%$ of the studies, approximately one-fourth of the patients could not be classified because of altered EEG char- 
acteristics in delayed diagnosis. ${ }^{[19]}$ It is thought that 1-6\% of NCSEs consist of absence and $44 \%$ of focal NCSE with impaired consciousness. ${ }^{[34]}$ Although focal NCSE with impaired consciousness has high mortality and morbidity in acute disease ${ }_{1}^{[4]}$ the need for aggressive treatment remains unclear. Recurrent seizures may increase the metabolic demand of the brain and cause neuronal loss. ${ }^{[1]}$ Therefore, treating NCSE can reduce these harmful effects. ${ }^{[1]}$ If NCSE can be demonstrated to cause brain damage, an aggressive treatment decision can be made. Otherwise, an aggressive treatment may increase NCSE morbidity ${ }^{[42]}$ As we could not find a relation between the causes of death of our patients and NCSE treatment, our observation of NCSE treatment response seems to support aggressive treatment, however, the treatment decision should be made according to the balance of benefits and side effects.

Our study has some limitations. The first is the low number of patients. Second, while most of the patients had a cEEG for more than $24 \mathrm{~h}$, some CEEGs $(16 / 40,40 \%)$ could not be extended to $24 \mathrm{~h}$ due to a lack of resources; therefore, maybe we could not diagnose a case or two. Especially in the case of unexplained coma, CEEG for longer than $24 \mathrm{~h}$ may increase the probability of detecting seizures and should be preferred for the NICU patients with risk of NCSE. The strength of our study is that patients were observed prospectively. We were able to document patients' clinical examinations, their response to treatment, and follow-up the results clinically.

Conclusion- EmEEG is a useful tool for NCSE screening in the NICU patients in the early phase of changes in consciousness. Low GCS or FS scores of the patients, epileptic seizures before admission to the NICU, the decreased level of consciousness at administration do not predict the presence of NCSE. In the presence of minor motor activity in a patient hospitalized in the NICU, the high risk of NCSE should be considered. The unfavorable prognosis of the patients at discharge or the formation of new neurological deficits probably depends on the underlying etiology and is not affected by the presence of NCSE. When there is no possibility of CEEG, early EmEEG with clinical suspicion of NCSE may be helpful for the diagnosis of NCSE. The presence of minor motor movements and EmEEG findings together can be useful tools to guide the high-risk NCSE patients to cEEG monitoring in NICU.

Informed Consent- Written, informed consent was obtained from the patient's family for the publication of this case report and the accompanying images.

Ethics Committee Approval- This study was approved by the ethical committee of the Ege University, Faculty of Medicine (date: 09.02.2011, no: 11-1.1/13).
Peer-review- Externally peer-reviewed.

Authorship Contributions- Concept: H.Ş.; Design: H.Ş., T.C.Ş.; Supervision: H.Ş.; Data collection \&/or processing: T.C.Ş.; Analysis and/or interpretation: T.C.S.., F.B.; Literature search:T.C.Ş.; Writing:T.C.Ş.; Critical review: H.Ş.

Conflict of interest- The authors declare that they have no conflict of interest.

Financial Disclosure: The authors declared that this study has received no financial support.

\section{References}

1. Sutula TP, Hagen J, Pitkänen A. Do epileptic seizures damage the brain? Curr Opin Neurol 2003;16(2):189-95. [CrossRef]

2. Claassen J, Mayer SA, Kowalski RG, Emerson RG, Hirsch LJ. Detection of electrographic seizures with continuous EEG monitoring in critically ill patients. Neurology 2004;62(10):174348. [CrossRef]

3. Pandian JD, Cascino GD, So EL, Manno E, Fulgham JR. Digital video-electroencephalographic monitoring in the neurological-neurosurgical intensive care unit: Clinical features and outcome. Arch Neurol 2004;61(7):1090-94. [CrossRef]

4. Shneker BF, Fountain NB. Assessment of acute morbidity and mortality in nonconvulsive status epilepticus. Neurology 2003;61(8):1066-73. [CrossRef]

5. Young GB, Jordan KG, Doig GS. An assessment of nonconvulsive seizures in the intensive care unit using continuous EEG monitoring: An investigation of variables associated with mortality. Neurology 1996;47(1):83-9. [CrossRef]

6. Dericioglu N, Arsava EM, Topcuoglu MA. Time to detection of the first seizure in patients with nonconvulsive status epilepticus in the neurological intensive care unit. Clin EEG Neurosci 2020;51(1):70-3. [CrossRef]

7. Cheng JY. Latency to treatment of status epilepticus is associated with mortality and functional status. J Neurol Sci 2016;370:290-5. [CrossRef]

8. Hirsch LJ, LaRoche SM, Gaspard N, Gerard E, Svoronos A, Herman ST, et al. American clinical neurophysiology society's standardized critical care EEG terminology: 2012 version. J Clin Neurophysiol 2013;30(1):1-27. [CrossRef]

9. Sutter R, Kaplan PW. Electroencephalographic criteria for nonconvulsive status epilepticus: Synopsis and comprehensive survey. Epilepsia 2012;53(Suppl 3):1-51. [CrossRef]

10. Trinka E, Cock H, Hesdorffer D, Rossetti AO, Scheffer IE, Shinnar $\mathrm{S}$, et al. A definition and classification of status epilepticus report of the ILAE task force on classification of status epilepticus. Epilepsia 2015;56(10):1515-23. [CrossRef]

11. Leitinger M, Beniczky S, Rohracher A, Gardella E, Kalss G, Qerama $E$, et al. Salzburg consensus criteria for non-convulsive status epilepticus approach to clinical application. Epilepsy Behav 2015;49:158-63. [CrossRef]

12. Shorvon S, Trinka E. The 5th london-innsbruck colloquium 
on status epilepticus and acute seizures. Epilepsy Behav 2015;49:1-3. [CrossRef]

13. Benbadis SR, Tatum WO 4th. Prevalence of nonconvulsive status epilepticus in comatose patients. Neurology 2000;55(9):1421-3.

14. Laccheo I, Sonmezturk H, Bhatt AB, Tomycz L, Shi Y, Ringel M, et al. Non-convulsive status epilepticus and non-convulsive seizures in neurological ICU patients. Neurocrit Care 2015;22(2):202-11.

15. Tuncer OG, Altindag E, Yildiz SO, Nalbantoglu M, Acik ME, Ozkan ST, et al. Reevaluation of the critically III patients with nonconvulsive status epilepticus by using salzburg consensus criteria. Clin EEG Neurosci 2018;49(6):425-32. [CrossRef]

16. Altindağ E, Okudan ZV, Özkan ST, Krespi Y, Baykan B. Electroencephalographic patterns recorded by continuous EEG monitoring in patients with change of consciousness in the neurological intensive care unit. Noro Psikiyatri Ars 2017;54(2):168-74.

17. DeLorenzo RJ, Waterhouse EJ, Towne AR, Boggs JG, Ko D, DeLorenzo GA, et al. Persistent nonconvulsive status epilepticus after the control of convulsive status epilepticus. Epilepsia 1998;39(8):833-40. [CrossRef]

18. Vespa PM, Nenov V, Nuwer MR. Continuous EEG monitoring in the intensive care unit: Early findings and clinical efficacy. J Clin Neurophysiol 1999;16(1):1-13. [CrossRef]

19. Narayanan JT, Murthy JM. Nonconvulsive status epilepticus in a neurological intensive care unit: Profile in a developing country. Epilepsia 2007;48(5):900-6. [CrossRef]

20. Varelas PN, Spanaki MV, Hacein-Bey L, Hether T, Terranova B. Emergent EEG: Indications and diagnostic yield. Neurology 2003;61(5):702-4. [CrossRef]

21. Varelas PN, Hacein-Bey L, Hether T, Terranova B, Spanaki MV. Emergent electroencephalogram in the intensive care unit: Indications and diagnostic yield. Clin EEG Neurosci 2004;35(4):173-80. [CrossRef]

22. Khan SF, Ashalatha R, Thomas SV, Sarma PS. Emergent EEG is helpful in neurology critical care practice. Clin Neurophysiol 2005;116(10):2454-9. [CrossRef]

23. Shafi MM, Westover MB, Cole AJ, Kilbride RD, Hoch DB, Cash SS. Absence of early epileptiform abnormalities predicts lack of seizures on continuous EEG. Neurology 2012;79(17):1796-801.

24. Westover MB, Shafi MM, Bianchi MT, Moura LM, O'Rourke D, Rosenthal ES, et al. The probability of seizures during EEG monitoring in critically ill adults. Clin Neurophysiol 2015;126(3):46371. [CrossRef]

25. Sansevere AJ, Duncan ED, Libenson MH, Loddenkemper T, Pearl PL, Tasker RC. Continuous EEG in pediatric critical care: Yield and efficiency of seizure detection. J Clin Neurophysiol 2017;34(5):421-6. [CrossRef]

26. Jette N, Claassen J, Emerson RG, Hirsch LJ. Frequency and predictors of nonconvulsive seizures during continuous electroencephalographic monitoring in critically ill children. Arch Neurol 2006;63(12):1750-5. [CrossRef]

27. Struck AF, Osman G, Rampal N, Biswal S, Legros B, Hirsch LJ, et al. Time-dependent risk of seizures in critically ill patients on continuous electroencephalogram. Ann Neurol 2017;82(2):177-85.
28. Zafar SF, Subramaniam T, Osman G, Herlopian A, Struck AF. Electrographic seizures and ictal-interictal continuum (IIC) patterns in critically ill patients. Epilepsy Behav 2020;106:107037.

29. Husain AM, Horn GJ, Jacobson MP. Non-convulsive status epilepticus: Usefulness of clinical features in selecting patients for urgent EEG. J Neurol Neurosurg Psychiatry 2003;74(2):189-91.

30. Carrera E, Claassen J, Oddo M, Emerson RG, Mayer SA, Hirsch LJ. Continuous electroencephalographic monitoring in critically III patients with central nervous system infections. Arch Neurol 2008;65(12):1612-8. [CrossRef]

31. Rossetti AO, Hurwitz S, Logroscino G, Bromfield EB. Prognosis of status epilepticus: Role of aetiology, age, and consciousness impairment at presentation. J Neurol Neurosurg Psychiatry 2006;77(5):611-5. [CrossRef]

32. Baysal-Kirac L, Feddersen B, Einhellig M, Rémi J, Noachtar S. Does semiology of status epilepticus have an impact on treatment response and outcome? Epilepsy Behav 2018;83:81-6. [CrossRef]

33. Atmaca MM, Bebek N, Baykan B, Gökyiğit A, Gürses C. Predictors of outcomes and refractoriness in status epilepticus: A prospective study. Epilepsy Behav 2017;75(2017):158-64. [CrossRef]

34. Knake S, Rochon J, Fleischer S, Katsarou N, Back T, Vescovi M, et al. Status epilepticus after stroke is associated with increased long-term case fatality. Epilepsia 2006;47(12):2020-6. [CrossRef]

35. Poothrikovil RP, Gujjar AR, Al-Asmi A, Nandhagopal R, Jacob PC. Predictive value of short-term EEG recording in critically ill adult patients. Neurodiagn J 2015;55(3):157-68. [CrossRef]

36. Dennis LJ, Claassen J, Hirsch LJ, Emerson RG, Connolly ES, Mayer SA. Nonconvulsive status epilepticus after subarachnoid hemorrhage. Neurosurgery 2002;51(5):1136-43; discussion 1144. [CrossRef]

37. Little AS, Kerrigan JF, McDougall CG, Zabramski JM, Albuquerque FC, Nakaji $P$, et al. Nonconvulsive status epilepticus in patients suffering spontaneous subarachnoid hemorrhage. J Neurosurg 2007;106(5):805-11. [CrossRef]

38. Ferguson M, Bianchi MT, Sutter R, Rosenthal ES, Cash SS, Kaplan PW, et al. Calculating the risk benefit equation for aggressive treatment of non-convulsive status epilepticus. Neurocrit Care 2013;18(2):216-27. [CrossRef]

39. Kaplan PW. Nonconvulsive status epilepticus. Neurology 2003;61(8):1035-6. [CrossRef]

40. Payne ET, Zhao XY, Frndova H, McBain K, Sharma R, Hutchison $J S$, et al. Seizure burden is independently associated with short term outcome in critically ill children. Brain 2014;137(5):142938. [CrossRef]

41. Al-Said YA, Baeesa SS, Shivji Z, Kayyali H, Alqadi K, Kadi G, et al. Non-convulsive seizures and electroencephalography findings as predictors of clinical outcomes at a tertiary intensive care unit in Saudi Arabia. Clin Neurol Neurosurg 2018;171:95-9. [CrossRef]

42. Litt B, Wityk RJ, Hertz SH, Mullen PD, Weiss H, Ryan DD, et al. Nonconvulsive status epilepticus in the critically ill elderly. Epilepsia 1998;39(11):1194-202. [CrossRef] 